\title{
Гибкость или производительность контрактного производства: дилемма разрешима?
}

Визит на сборочно-монтажное производство

компании ООО "Нанотех"

Ю. Ковалевский

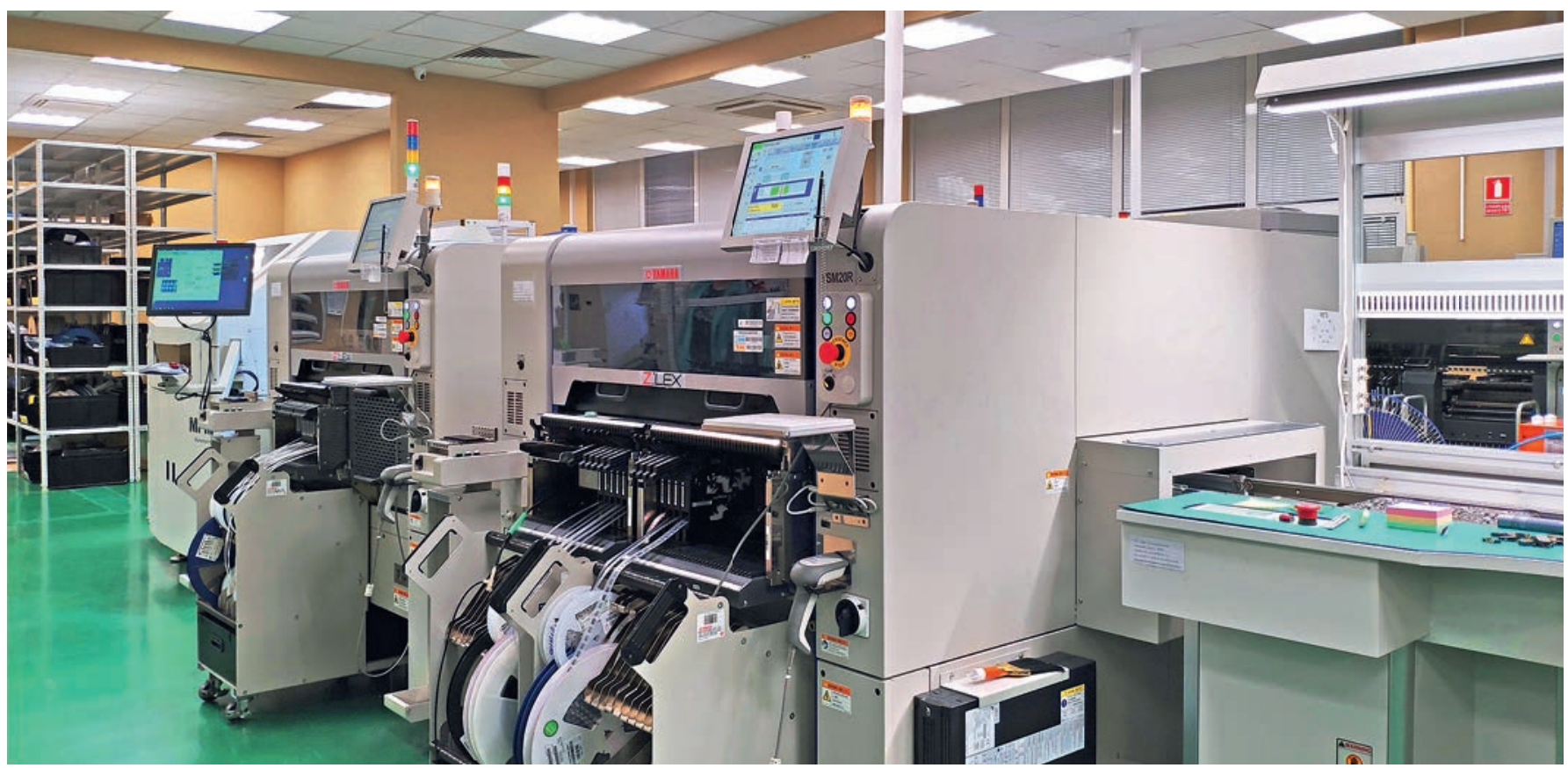

Белорусская компания ООО "Нанотех" является ведущим контрактным сборщиком электроники на территории республики. Как любому контрактному производителю, ей приходится иметь дело с частой переналадкой оборудования при запуске в производство новых заказов. Проводя в жизнь принцип уделять каждому изделию даже в крупной партии такое внимание, как будто это единичное изделие, компания, тем не менее, построила свое производство и расширяет его далее с использованием среднесерийного оборудования. Как это производство организовано и каким образом компании удается обеспечивать его гибкость и достигать высокого качества продукции, нам показал начальник производственного участка ООО “Нанотех" Андрей Александрович Канашевич.

Андрей Александрович, когда ваша компания стала оказывать услуги контрактного производства?

С2012 года. Компания «Нанотех» была создана в 2006 году и изначально занималась поставкой печатных плат и трафаретов для нанесения паяльной пасты. Мы подготавливали заказы наших клиентов к производству, затем передавали их нашим партнерам в Китае, готовые платы и трафареты доставляли в Беларусь и отгружали заказчикам. Этим направлением наша компания успешно занимается и сейчас.

Создание сборочно-монтажного производства началось в 2011 году. Оно сразу задумывалось как контрактное. Было закуплено оборудование, выстроена первая автоматизированная линия поверхностного монтажа, 
организован участок ручного монтажа штыревых компонентов, и уже в начале следующего года на новом производстве стартовала сборка печатных узлов. На тот момент на производстве было пять монтажников и только одна линия поверхностного монтажа с одним автоматом Assembleon с паспортной производительностью 19 тыс. комп. / ч и фактической - порядка 10 тыс. комп. / ч. Всё производство помещалось на 300 м².

Сейчас у нас уже три линии поверхностного монтажа, в которых в общей сложности пять автоматов с суммарной паспортной производительностью около 220 тыс. комп./ч. Количество монтажников возросло до 20. Увеличилась и производственная площадь: в настоящее время производство расположено на двух этажах, занимая примерно 450 м² на одном этаже и более

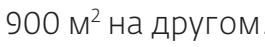

Помимо монтажа печатных узлов, на этих площадях мы выполняем и некоторые сопутствующие операции, такие как, например, изготовление кабельной продукции, программирование микроконтроллеров на печатных узлах, функциональное тестирование. Но основное производственное направление - всё же поверхностный монтаж и монтаж штыревых компонентов.

Что стало причиной расширения производства? Увеличилось количество заказчиков?

Конечно, со временем клиентская база постепенно расширялась. В этом заслуга нашего отдела продаж.

Но есть и еще один важный фактор: росли и наши клиенты, количество заказов от них увеличивалось. В это и мы внесли свой вклад: некоторые заказчики нам прямо сообщали, что качество нашей сборки способствовало их выходу на новые рынки, увеличению их объемов продаж.

Когда стало ясно, что производительности изначально установленной линии нам не хватает, для нее был закуплен второй автомат. Затем стало недостаточно и этого, и компания приобрела вторую линию. Когда же встал вопрос о необходимости третьей линии, оказалось, что нужно расширять площадь производства, что и было сделано.

\section{Какого размера партии вы собираете? Как часто при- ходится переналаживать линии с одного изделия на другое?}

Мы берем в работу заказы от одной штуки, и даже один печатный узел мы собираем на автоматизированных линиях, конечно если на нем не пара десятков компонентов. Вообще, это наш подход: мы работаем с одним изделием так же, как с тысячами, а с тысячами - так же, как с одним. То есть наше внимание к каждому конкретному изделию, а, следовательно, и качество сборки не зависят от объема партии.
Если говорить о максимальном объеме партии это порядка 10-20 тыс. изделий. Больше у нас бывает редко. Не потому, что мы поставили такую планку, а потому, что даже если заказчику нужно собрать больше, как правило, он разбивает такой заказ на несколько партий. Поэтому и переналадки у нас достаточно частые: обычно две-три на каждой линии за рабочий день - две смены. Это не считая перена-

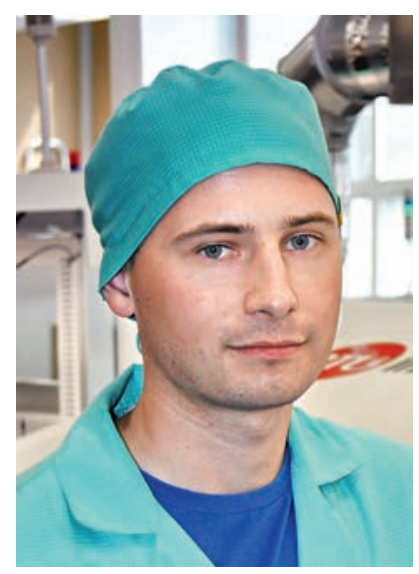

Андрей Канашевич ладок при переходе с одной стороны узла на другую, если монтаж двусторонний.

И при таких частых переналадках вы используете автоматы, которые позиционируются как оборудование для среднесерийных производств. Почему вы выбрали эти установки?

Я не участвовал в выборе оборудования для первой линии: когда я пришел в компанию, эта линия уже работала. Но могу сказать, что первый приобретенный автомат - MC-1 торговый марки Assembleon, под которой до 2011 года поставлялось на европейский и американский рынок оборудование компании Yamaha - очень хорошо зарекомендовал себя в отношении как механической, так и программной части. Не бывает оборудования, с которым вообще нет проблем, но с этой установкой, если какие-либо вопросы и возникали, они достаточно быстро решались, и ктому времени, когда возникла потребность в расширении парка оборудования, с ним никаких серьезных проблем ни разу не возникло.

Эта была одна из основных причин того, что было решено приобрести автоматы Yamaha также и для новых линий. Вообще, опыт эксплуатации оборудования самой первой линии показал его высокую надежность, достаточную гибкость, а также высокое качество работы. Поэтому при покупке нового оборудования не стоял вопрос выбора производителей - мы выбирали только функционал и опции, за исключением, разве что, печей оплавления: для первой линии у нас была закуплена семизонная печь Seho, а для новых линий мы выбрали более длинные печи компании ВTU.

Вторая важная причина заключалась в том, что мы стремились обеспечить гибкость при распределении работ по линиям. Благодаря тому, что в линиях стоит оборудование от одного и того же производителя, мы имеем единое для всех автоматов программное обеспечение, которое позволяет гибко переносить сборку изделия 
с одной линии на другую в зависимости от объема партии, при этом не нужно плодить управляющие программы в разных форматах, конвертировать их. Самое главное, что точность и повторяемость работы даже самого первого установленного оборудования не уступает самым "свежим" установкам.

Кроме того, нет необходимости содержать парк различных питателей и можно переставлять их с одной линии на другую по мере необходимости. Здесь хочется отметить то, что Yamaha, несмотря на смену нескольких поколений автоматов-установщиков, оставила обратную совместимость для питателей. Таким образом, все питатели, имеющиеся на производственном участке, подходят ко всем автоматам. В условиях большой номенклатуры, характерной для контрактного производства, это очень немаловажный фактор.

Конечно же, помимо качества оборудования и соображений унификации, большую роль сыграла и репутация поставщика. За время работы с компанией "АссемРус" у нас никогда не было проблем с технической поддержкой и решением тех или иных вопросов. Всё делалось качественно и в оговоренные сроки

Но всё же это серийное оборудование, а о таком оборудовании существует мнение, что оно не предназначено для частых переналадок, что оно требует существенных временнь́х затрат при подготовке запуска новой партии.

Возможно некоторые решения, специально спроектированные для изготовления малых партий, позволяют выполнять переналадки быстрее. Однако на данный момент мы довели время переналадки с одного изделия на другое до одного-двух часов. Это время с лихвой компенсируется производительностью автоматов и удобством их настройки и эксплуатации. При этом наши линии в любой момент готовы к сборке очень крупных партий, когда такие заказы появляются. На менее производительном,

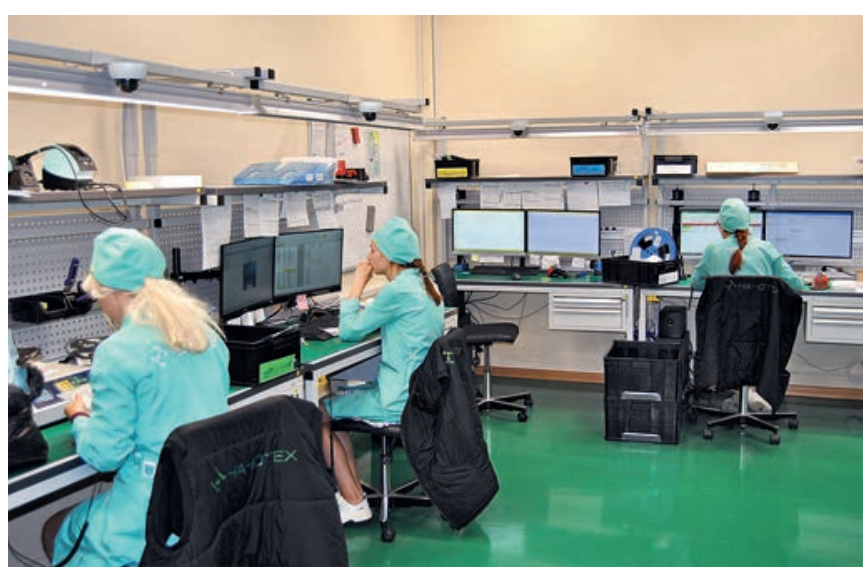

Рабочие места на участке входного контроля пусть и более гибком оборудовании, осуществлять монтаж крупных партий было бы весьма затруднительно.

Более того, час на переналадку - это не предел. Мы можем сократить данное время по меньшей мере еще вдвое, но это потребует дополнительных организационных мер, а на данный момент у нас в этом нет необходимости.

Вообще, организация подготовки производства пожалуй, самый важный фактор в снижении времени переналадки.

Тогда, может быть, покажете, как это организовано у вас на практике?

Давайте начнем с самого начала - с входного контроля и подготовки комплектации.

Комплектация, которая приходит на производство, поступает на участок входного контроля. Здесь она пересчитывается, проверяется, каждая упаковка маркируется этикеткой со штрихкодом, по которому компоненты будут далее регистрироваться в информационной системе производства. От этих штрихкодов зависит правильность монтажа, поэтому все этикетки повторно проверяются. Причем проверку выполняет обязательно другой сотрудник, и правом такой проверки обладает всего пять человек - это самые квалифицированные специалисты на этом участке.

Проверка включает не только сверку нашего штрихкода с этикеткой поставщика. Бывают ситуации, когда заводской этикетки просто нет либо она не соответствует тому, что на самом деле находится в упаковке. Иногда встречаются ситуации с некорректными номиналами компонентов, иногда с типами компонентов. Человеческий фактор никто не отменял, и, если такая ошибка будет пропущена, ее не исправит никакая информационная

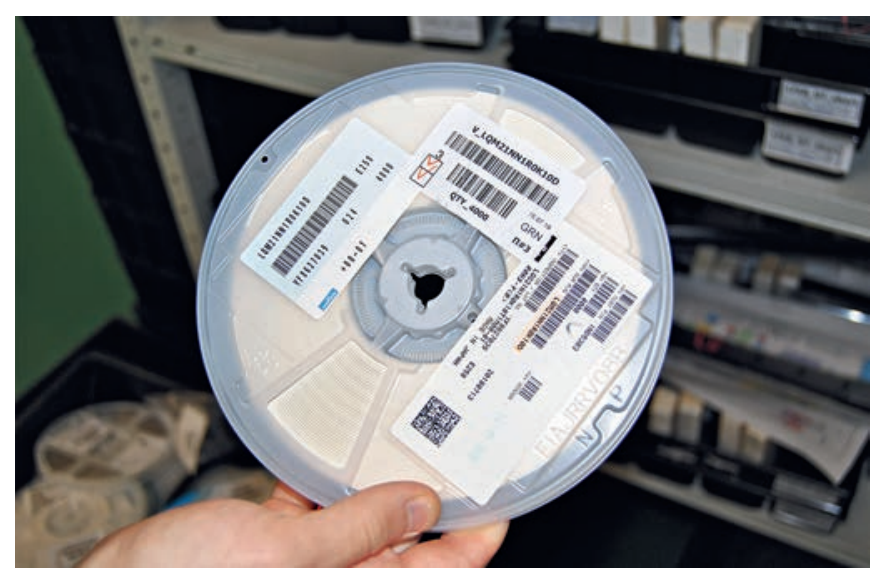

Катушка с идентификационной этикеткой. "Галочки" означают, что данная упаковка проверена. Первая "галочка" отвечает за типономинал, вторая - за количество. Цвет "галочек" указывает на то, кем выполнялась проверка 
система. Поэтому мы обязательно проверяем соответствие нашей этикетки компонентам, находящимся в упаковке. Если на компоненте указано полное наименование, проверка происходит по данной маркировке. Если номинал не указан, как, например, на чип-конденсаторах, выполняется измерение его характеристик. Если же речь идет о кодовом обозначении на компоненте, мы сверяем маркировку на нем с маркировкой, указанной в документации производителя компонента.

На стеллажах комплектация отмечается различными цветами, которые обозначают ее статус: готова ли она для передачи на производство, проходит проверку или просто находится на хранении.

Все эти процедуры выполняются сразу по приходу комплектации на участок, чтобы в случае выявления несоответствий было время их исправить и для заказчика это не было сюрпризом.

Здесь же выполняется подготовка комплектации для ручного монтажа - раскладывание компонентов

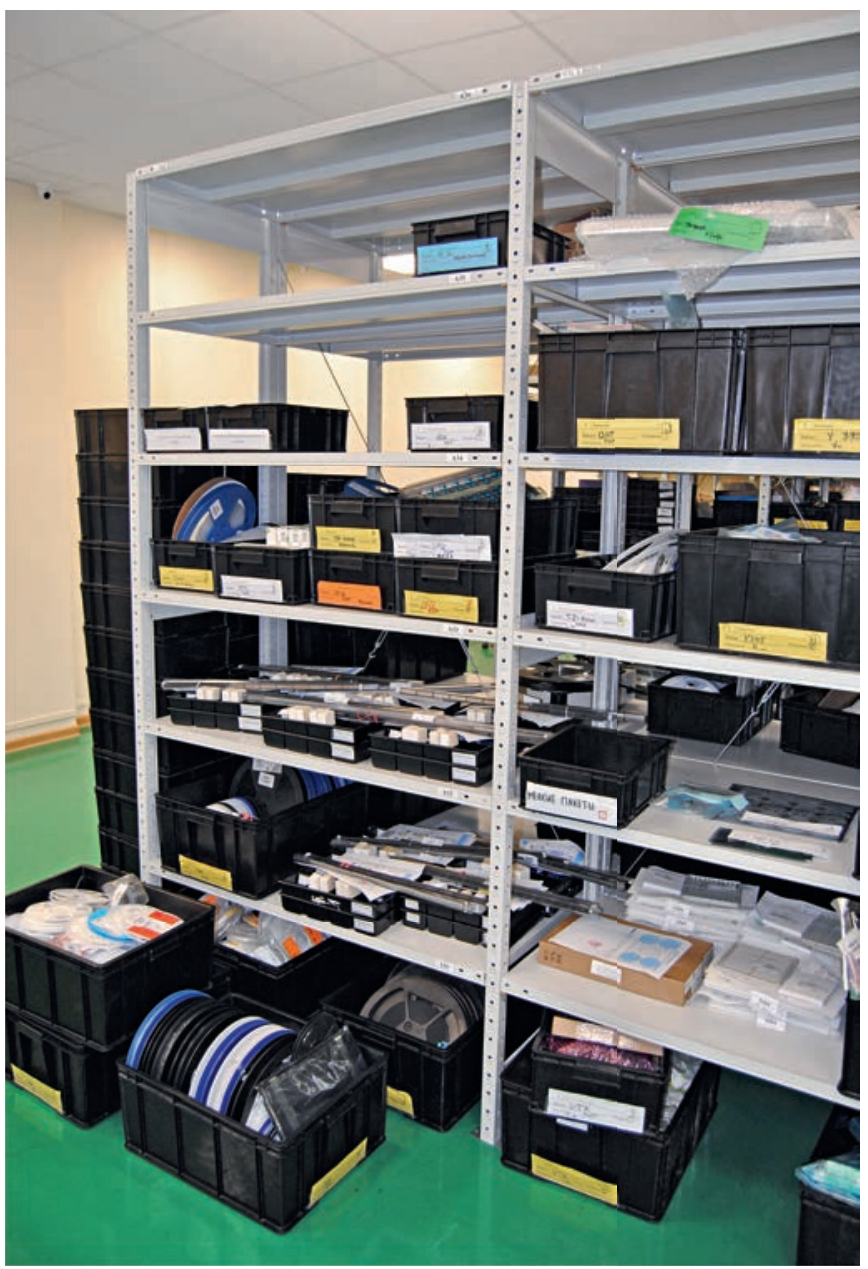

Стеллажи с комплектацией на участке входного контроля. Цвет этикеток указывает на статус каждого ящика с комплектацией в специальные антистатические поддоны согласно спецификациям на изделия.

По завершении монтажа заказа остатки комплектации поступают также на этот участок, после чего пересчитываются, маркируются и либо хранятся до следующего заказа, либо отправляются заказчику. При этом, даже если заказчик возвращает нам упаковки с нашей маркировкой через относительно непродолжительное время, мы заново выполняем всю процедуру проверки и клеим новые этикетки, чтобы не возникло проблем из-за того, что с комплектацией что-то произошло, пока она находилась вне нашего производства.

Компоненты к вам приходят только от заказчиков или вы также оказываете услуги по комплектации?

Раньше мы работали только с компонентами от заказчиков, но около трех лет назад у нас стало активно развиваться направление поставки комплектации, появился собственный отдел закупки компонентов. Это позволяет снять с заказчика ряд вопросов по поиску компонентов, их закупке, доставке, согласованию сроков поставки компонентов, печатных плат, а также сроков монтажа. Закупая компоненты только у проверенных европейских поставщиков, мы можем минимизировать риски, связанные с некачественной комплектацией или со срывом сроков поставки.

\section{Что происходит с комплектацией далее?}

С участка входного контроля она перемещается на участок поверхностного монтажа, а конкретнее - на участок подготовки комплектации к автоматическому монтажу. На данном участке компоненты заряжаются в питатели и регистрируются в информационной системе для того, чтобы автоматическое оборудование "знало", в какой питатель какой компонент заряжен. Также здесь

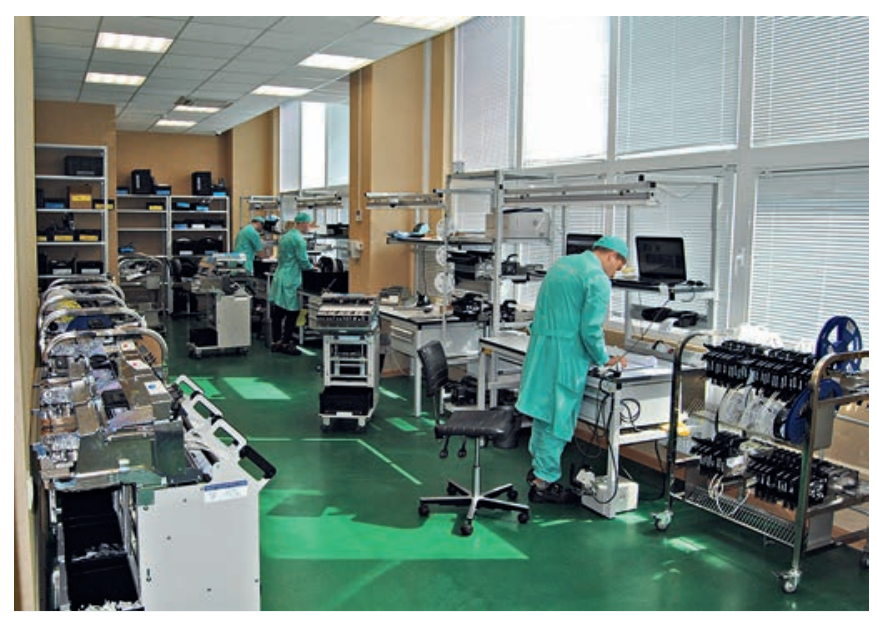

Участок подготовки комплектации к автоматическому монтажу 


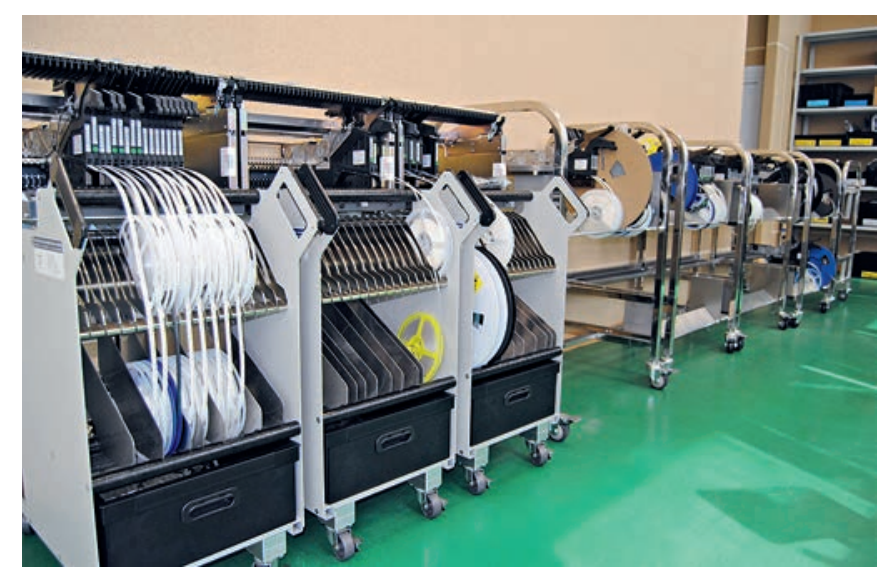

Подкатные FES-тележки - один из эффективных инструментов сокращения времени переналадки линий

готовятся к монтажу пластиковые пеналы и матричные поддоны с комплектацией. Заряженные питатели размещаются в подкатных FES-тележках. с такими тележками могут работать две из трех наших линий. С одной из линий приходится работать по «классической» схеме: в ней питатели загружаются в автоматы по одному.

У нас достаточно много питателей, чтобы готовить их без прерывания работы линий. В подавляющем большинстве случаев мы можем работать сразу с тремя комплектами для каждой линии: один комплект готовится, второй находится в работе, третий разряжается после сборки предыдущей партии.

На каждом рабочем месте зарядки питателей есть приспособление и наборы заправочных концов для наращивания обрезков лент. Мы прекрасно понимаем, что

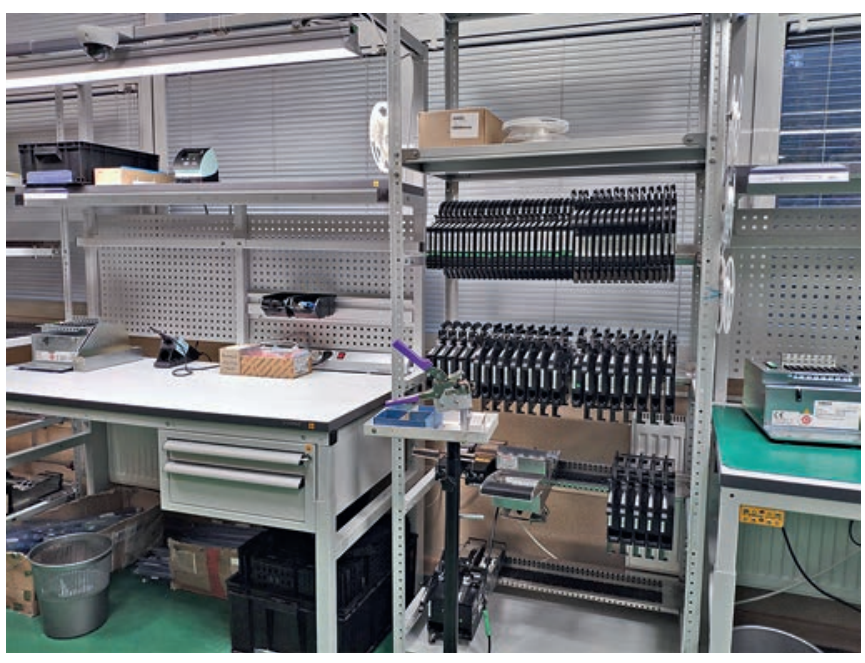

Один из стеллажей с питателями. Наличие большого количества питателей позволяет выполнять подготовку партий к запуску в производство заранее, без остановки оборудования для сборки партии из нескольких печатных узлов заказчик не будет покупать новые катушки с тысячами компонентов. Работа с обрезками лент, конечно, усложняет процесс, но не настолько, чтобы это было серьезной проблемой, а автоматы в наших линиях совершенно спокойно работают с обрезками, если их правильно подготовить

Также на этом участке выполняется верификация питателей. FES-тележка подключается к компьютеру, производится считывание данных из питателей и выявляются несоответствия, если они есть. Поэтому такие ошибки можно исправить заранее, до того, как тележка будет установлена в автомат и начнется монтаж.

Подготовка питателей вне линии и есть то организационное решение, которое позволяет свести к минимуму время простоя оборудования при переналадке?

Да, в сочетании с использованием FES-тележек это значительно сокращает время переналадки. Но это не единственное решение, которое нам позволяет быстро переходить на изготовление следующих изделий. Мы постарались вынести в оффлайн всё, что можно делать вне линии. В этом нам помогает система оффлайнпрограммирования. Мне известно, что на ряде предприятий создание управляющих программ выполняется непосредственно на оборудовании, по «живой» плате, на что может уходить несколько часов, а иногда и смен.

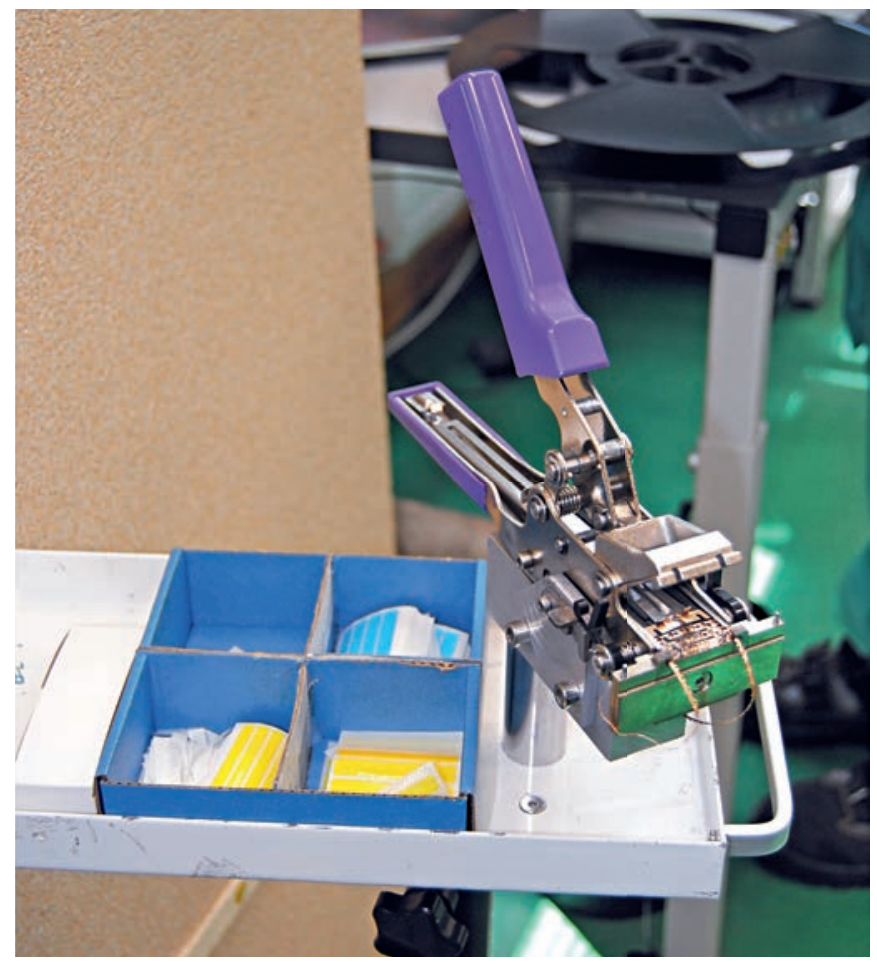

Инструмент для наращивания обрезков лент 


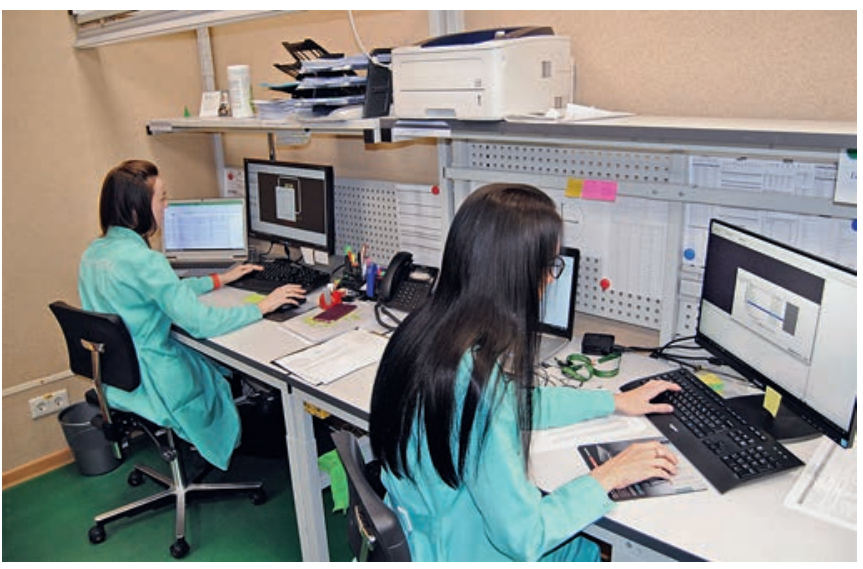

Подготовка управляющих программ для оборудования выполняется на отдельных рабочих местах вне линии

У нас же программы не только готовятся, но и полностью проверяются вне линии. Контролируется полное соответствие управляющей программы документации на печатный узел: позиционные обозначения, наименования компонентов, координаты и углы установки. Софт позволяет выявить такие моменты, как, например, несоответствие корпуса компонента контактным площадкам или перекрытие компонентов, когда разработчик не учел истинные размеры корпуса. Всё это делается заранее; если изделие комплектуем мы - еще до закупки комплектации. Это позволяет производству быть достаточно гибким, чтобы эффективно собирать даже единичные изделия на серийном оборудовании

Подготовка программ осуществляется в помещении, расположенном рядом с участком подготовки комплектации к автоматическому монтажу. Здесь же находится руководство этой части производства, отсюда осуществляется управление линиями, распределение задач между сотрудниками

Вы сказали, что бо́льшая часть оборудования во всех трех линиях от одних и тех же производителей. Но всё же состав линий немного разный. Чем линии отличаются друг от друга и существует ли некая специализация у каждой из них?

Начнем с первой линии. Всё оборудование в ней - от известных мировых производителей. Установка трафаретной печати со встроенной системой контроля отпечатков - Momentum американской фирмы МРМ; автоматы - Assembleon MC-1 и Yamaha YS12; печь немецкая, Seho - с семью зонами нагрева и двумя зонами охлаждения. Что касается конвейерных систем - это Южная Корея, фирма Kiheung.

Автомат MC-1 был приобретен самым первым, но он до сих пор великолепно справляется со своими задачами, хотя и уступает другим нашим автоматам по производительности и некоторым возможностям. Всё оборудование на производственном участке приобреталось совершенно новым, поэтому до выработки его ресурса еще достаточно далеко. Поскольку в линии два автомата с разной производительностью, задачи между ними распределяются так, чтобы монтаж производился синхронно. По точности установки автоматы имеют примерно одинаковые характеристики, поэтому данный фактор на распределение задач особого влияния не оказывает. Мы используем автоматический оптимизатор, который распределяет компоненты по автоматам.
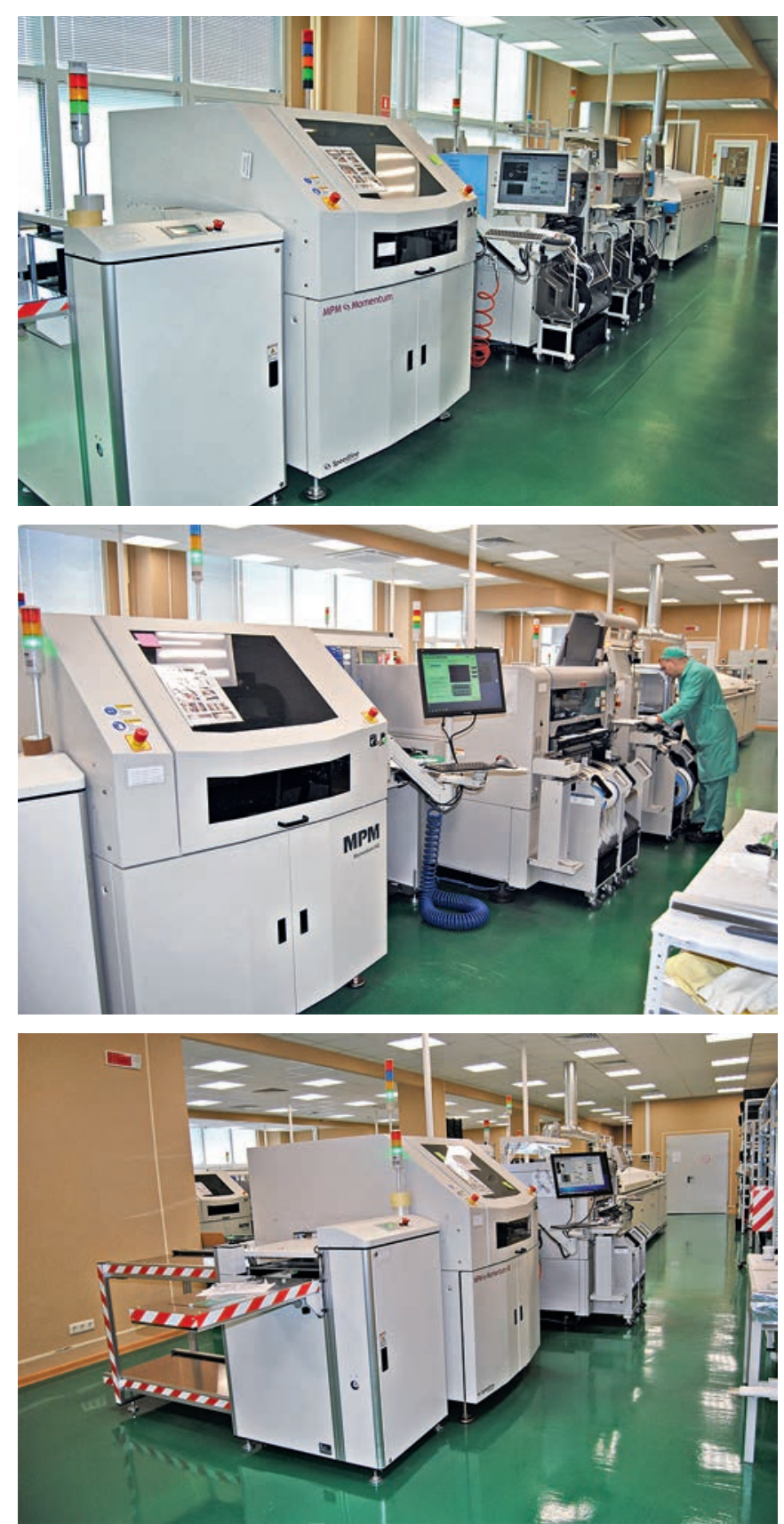

Общий вид линий поверхностного монтажа компании 


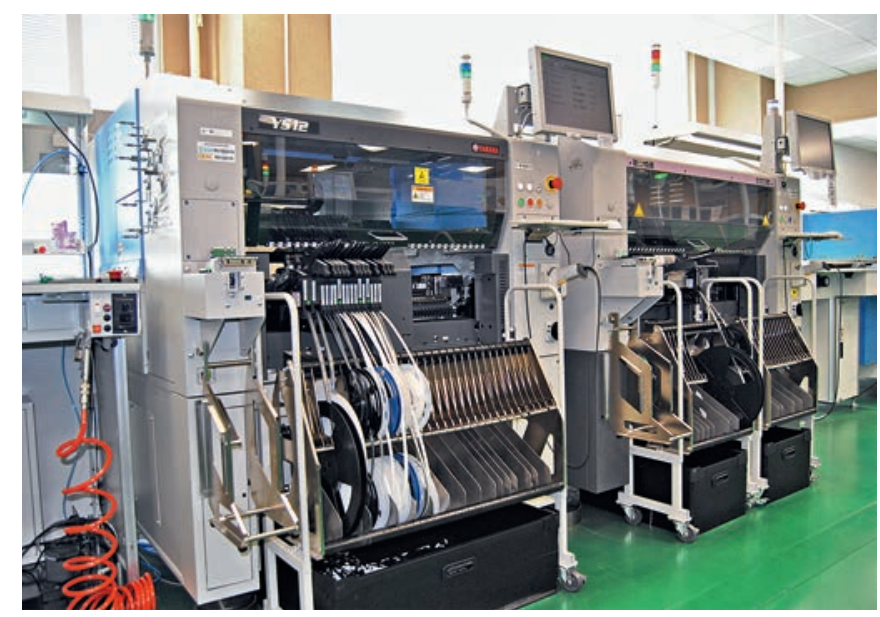

Автоматы в первой линии: слева - чип-шутер Yamaha YS12; справа - самый первый автомат компании, Assembleon MC-1

Обычно мелкие компоненты достаются первому автомату в линии, более крупные - второму. Кроме того, первый автомат - YS12, играющий роль чип-шутера, paботает только с лентами, а МС-1 может ставить компоненты как из лент, так и из пеналов, а с задней стороны у него расположен питатель из матричных поддонов. Единственное, с чем они не работают - это россыпь. Компоненты из россыпи при необходимости устанавливает оператор на рабочем месте далее по линии, но такая необходимость возникает редко, потому что, если заказчик предоставил нам компоненты в россыпи и их можно, например, упаковать в пенал, мы это делаем разумеется, заранее.

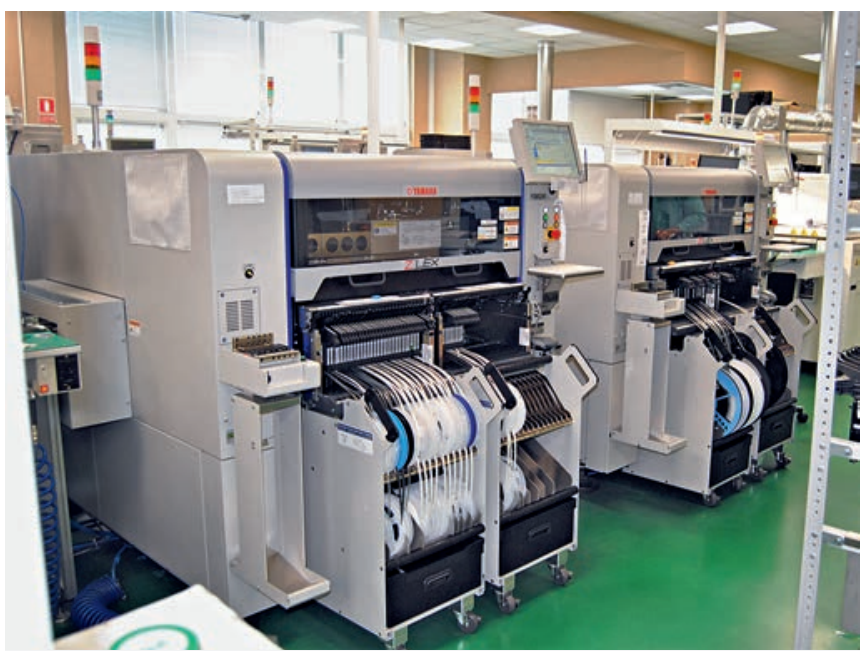

Самые новые автоматы компании, установленные во второй линии, - Yamaha YSM20R. Слева - двухпортальный; справа - автомат с одним порталом и питателем из матричных поддонов

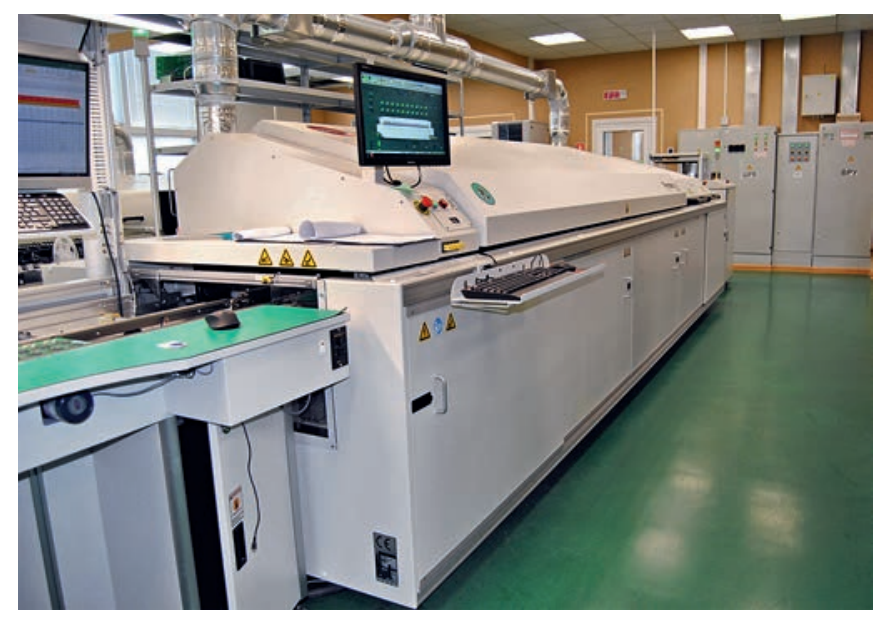

Печь Pyramax 125A компании ВTU с десятью зонами нагрева и тремя зонами охлаждения

Вторая линия составлена из самого нового оборудования, закупленного в конце 2018 года. Запустили мы ее 1 февраля 2019 года. Структура линии в целом такая же, как у первой, но оборудование здесь более производительное и с дополнительными опциями. Оба автомата - YSM20R, это последняя на сегодняшний день модель фирмы Yamaha в этой линейке. Они имеют разную конфигурацию: первый автомат двухпортальный с четырьмя местами под подкатные тележки, а второй имеет один портал и три места под тележки плюс питатель из матричных поддонов. В сумме такая конфигурация позволяет загрузить в линию до 224 питателей из лент 8 мм, а также до 30 матричных поддонов, что позволяет работать с очень насыщенными изделиями.

Печь оплавления в этой линии десятизонная, Pyramax 125A. Причина, по которой мы перешли на печи другого производителя заключается в том, что мы не смогли найти в линейке Seho достаточно длинных печей за приемлемую стоимость. Кроме того, у этой печи больше зон охлаждения, и на выходе мы получаем изделия почти комнатной температуры.

Третья наша линия похожа на вторую, но в ней только один автомат - ҮSM20.

Действительно, у каждой линии в некотором смысле есть своя специализация, которая определяется составом оборудования. Если необходимо собрать изделие, в котором мало компонентов, но заготовка достаточно крупная, лучше всего для этого подойдет третья линия, поскольку в таких случаях при наличии двух автоматов самым медленным звеном может оказаться печь оплавления. Типичный пример таких изделий - светодиодные светильники некоторых типов. Если узел очень насыщенный, для его сборки оптимальной будет вторая линия - самая производительная с точки зрения 
установки компонентов. Для промежуточных вариантов хорошо подходит первая линия.

Почему вам потребовалась печь с количеством зон нагрева больше семи? Это было связано с бессвинцовой пайкой?

Нет. Семизонная печь вполне справляется с бессвинцовыми профилями, но чем больше зон, тем более качественный профиль удается получить и тем проще использовать типовые профили для различных, но близких по своим параметрам изделий. А это немаловажно для контрактного производителя, ведь подготовка производства - это не только составление программ для автомата и загрузка питателей, но и подбор термопрофиля.

У нас на данный момент более 20 отработанных термопрофилей. В зависимости от состава припоя, типов и плотности компонентов, размеров групповой заготовки и толщины платы можно выбрать наиболее подходящий профиль, и в большинстве случаев он не потребует дополнительной коррекции. В некоторых экзотических случаях, конечно, дорабатывать профиль приходится, но всё равно есть, от чего оттолкнуться.

Кроме того, печи с бо́льшим количеством зон, как правило, длиннее, а значит производительнее. Семизонная Seho иногда становилась узким местом линии даже с не самыми производительными автоматами, и она уж точно не справилась бы с производительностью двух автоматов с тремя порталами в сумме. Поэтому при покупке новых печей мы выбирали только модели с суммарной длиной зон нагрева более трех метров.

Как отрабатывается профиль, если вы собираете единичное изделие?

Мы проверяем термопрофиль с помощью температурных датчиков, закрепленных на пустой плате или на плате с компонентами, но без припоя. Перед этим мы подробно изучаем применяемую в изделии элементную базу. Как правило, достаточно выбрать отработанный профиль для похожей платы в качестве базового и либо использовать как есть, либо незначительно скорректировать.

Есть еще одна подготовительная операция, часто занимающая длительное время при подготовке производства, - программирование АОИ.

Да, действительно, когда мы только приобрели систему АОИ, мы посчитали, что автоматическая инспекция имеет смысл, начиная только с относительно больших партий, потому что программировать АОИ ради десяти плат слишком долго. Казалось, за это время можно рассмотреть данные узлы под микроскопом

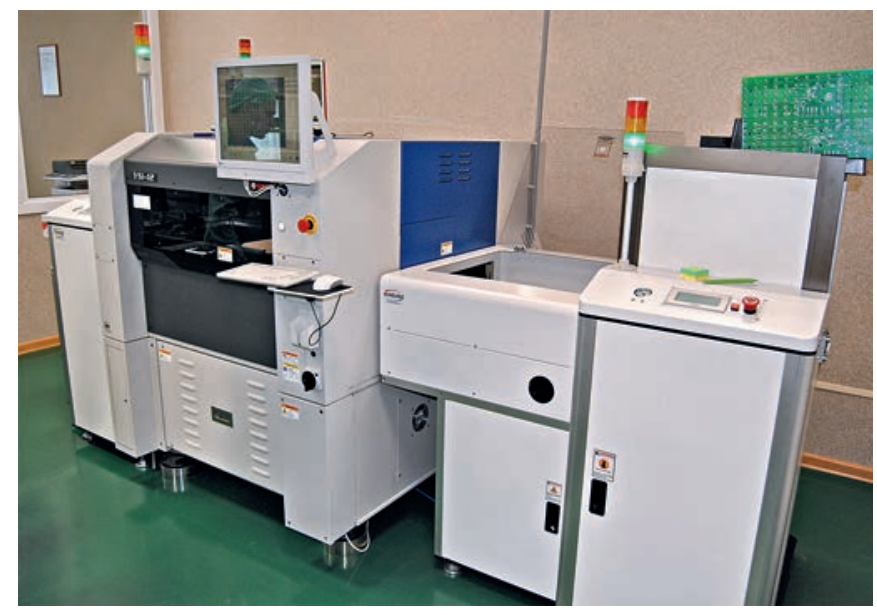

Установка 2D-АОИ YSi-12. На входе и выходе системы установлены, соответственно, загрузчик и разгрузчик

вдоль и поперек. Но в определенный момент мы изменили свое мнение. Во-первых, разрослась библиотека компонентов, и писать программы стало намного проще. А во-вторых, проанализировав заказы, мы поняли, что необходимость в автоматическом контроле есть и для единичных изделий. В таких случаях высока вероятность ошибки в комплектации, а на плате может быть более тысячи компонентов, плюс плата может быть унифицированной под несколько разных исполнений, и не на все посадочные места будут устанавливаться компоненты. В этих условиях выявить отсутствие отдельного компонента или его неверный типономинал визуально очень сложно даже на одной плате.

Поэтому сейчас мы пишем программы даже для одного узла и делаем это тоже оффлайн, не останавливая работу АОИ.

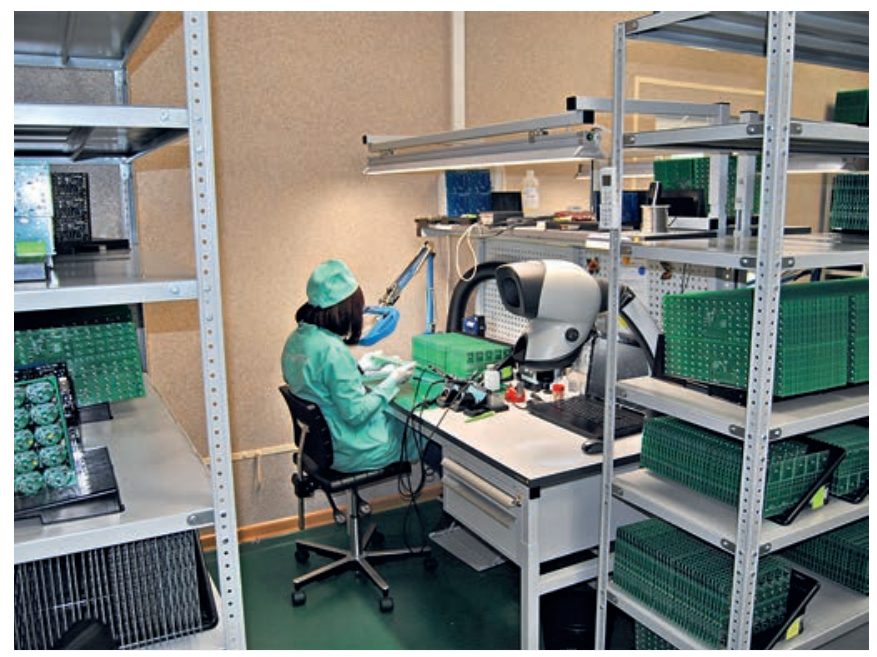

Рабочее место визуального контроля и устранения дефектов 


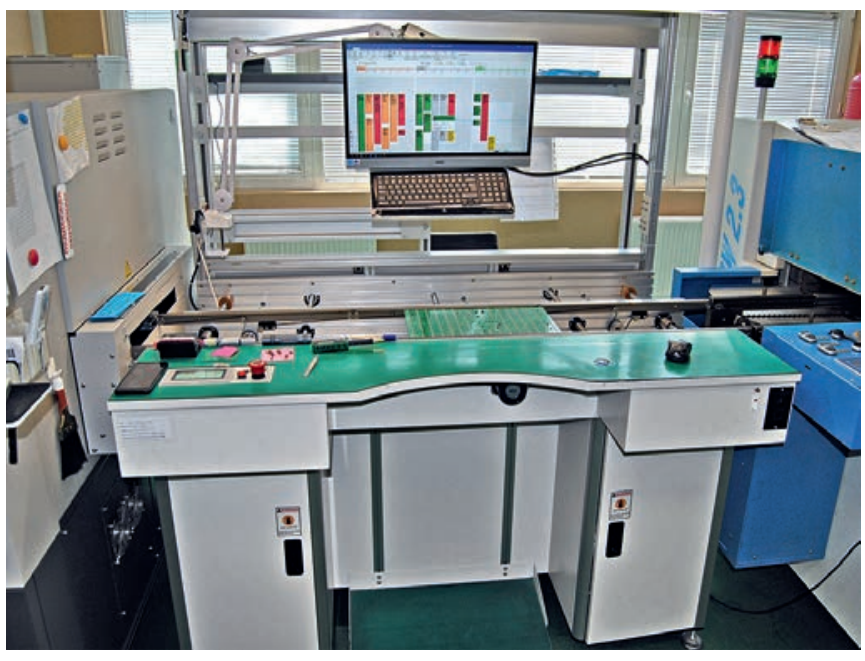

Рабочее место для контроля и устранения несоответствий перед оплавлением в составе линии

Мы выполняем контроль 100\% изделий во всех партиях как на системе АОИ, так и визуально. При этом на визуальном контроле мы сосредоточены на качестве пайки, поскольку любая система 2D-AOИ имеет ограничения по выявлению дефектов паяных соединений. Технологии АОИ продвинулись далеко вперед, и приобретение новой, трехмерной установки - один из приоритетных планов на будущее.

Когда у нас появится система 3D-AOИ, имеющуюся установку мы встроим в одну из линий перед печью. Сейчас у нас в этой позиции каждой линии есть рабочее место оператора, где он проверяет каждое изделие на предмет качества установки компонентов перед пайкой, поскольку исправление дефектов на этом этапе намного проще и дешевле, чем уже на спаянном печатном узле. Установка АОИ в этой позиции позволит проверять каждый компонент на каждой плате и тем самым минимизировать количество потенциальных дефектов.

По завершении поверхностного монтажа изделия передаются на ручной монтаж компонентов в отверстия. Какие существуют меры по повышению эффективности этой операции в условиях контрактного производства?

Да, после разделения групповых заготовок изделия передаются в руки монтажников, если, конечно, это требуется в заказе.

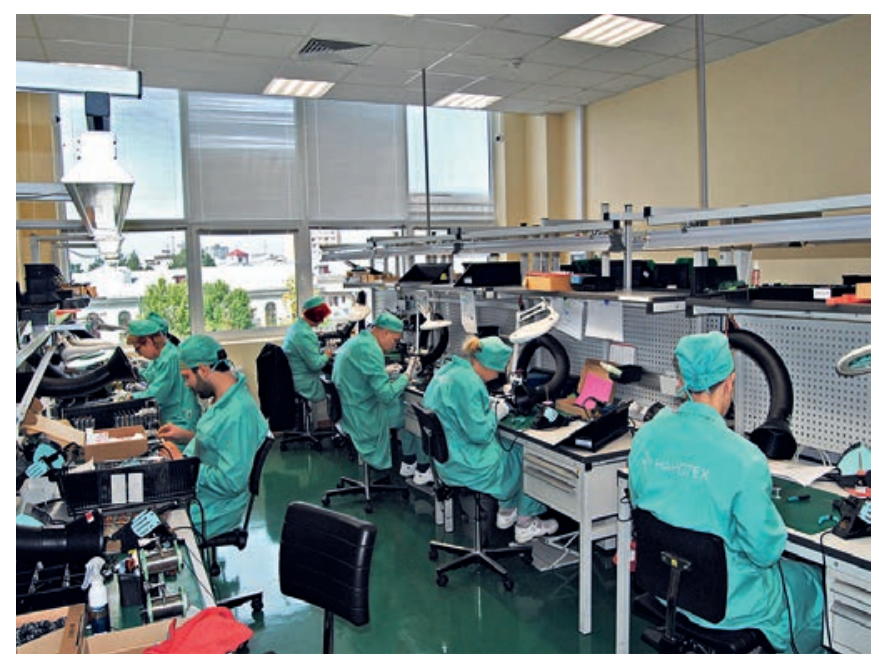

Участок ручного монтажа

На каждом рабочем месте монтажника у нас имеется весь необходимый набор оборудования и инструментов за исключением специальной оснастки, которая, разумеется, хранится отдельно и выдается по необходимости.

Оснастка - это один из способов существенно повысить качество и производительность в определенных случаях. Например, если требуется установить ряд светодиодов на определенную высоту, потому что они должны сопрягаться с корпусом изделия, можно это сделать, используя подставки, устанавливаемые под корпус каждого светодиода. Однако это достаточно трудозатратно и, кроме того, не гарантирует одинаковой высоты до верхней точки светодиода, потому что размер корпуса
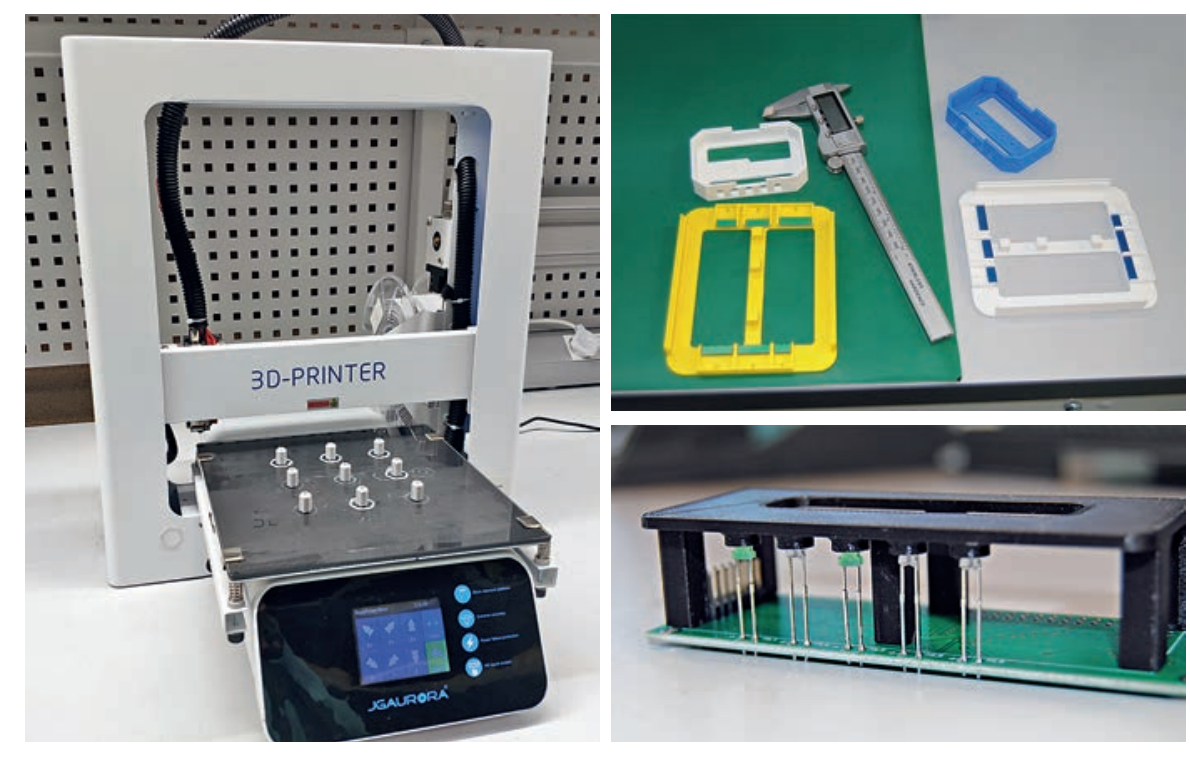

3D-принтер (слева), примеры изготовленной на нем оснастки (справа вверху) и светодиоды, установленные на плату на определенную высоту с помощью оснастки (справа внизу) 


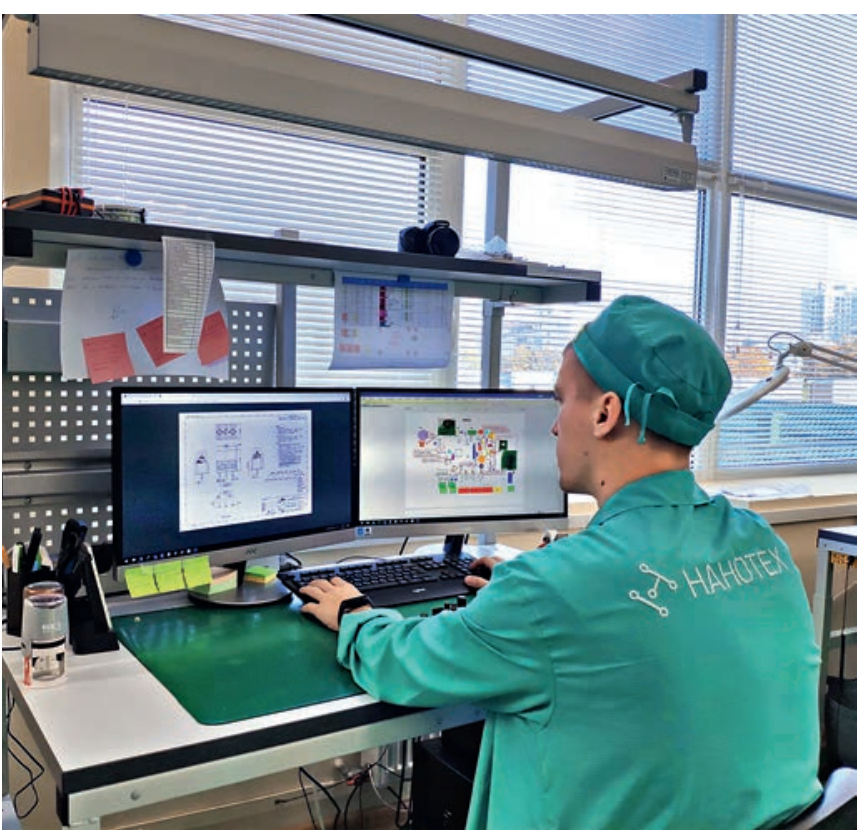

Подготовка документации для ручного монтажа

компонента может иметь отклонения. Да и ровность установки подставки под светодиод в ряде случаев не дает нужной точности.

Мы под такие изделия изготавливаем оснастку, фактически имитирующую часть корпуса. Установка светодиодов на заданную высоту в этом случае выполняется всего в несколько действий: вставить светодиоды в отверстия в плате, установить оснастку, перевернуть плату так, чтобы корпуса светодиодов вошли в отверстия в оснастке, припаять их и снять оснастку.

Для изготовления оснастки мы используем 3D-принтер. Подготовка модели и печать занимают всего пару часов. И это относительно дешевое решение: 3D-принтер стоит не так дорого.
Еще одно решение, которое позволяет повысить эффективность труда монтажников, - правильная подготовка технологической документации. Мы считаем, что монтажник не должен разбираться в чертежах, перелистывать их в поисках нужной информации, гадать, что хотел сказать конструктор. У нас инженеры заранее подготавливают чертеж платы с изображениями всех устанавливаемых компонентов с необходимыми размерами и даже фотографиями тех мест, которые могут вызвать затруднения, по возможности располагая всё на одном листе. Этот чертеж распечатывается на цветном принтере, что позволяет монтажнику легче воспринимать информацию

После выполнения ручного монтажа у нас также выполняется контроль 100\% изделий.

Вы рассказали нам сегодня о том, как развивалось ваше производство, и показали ряд решений для повышения его гибкости и обеспечения качества продукции. Какие шаги в дальнейшем развитии у вас намечены на ближайшее время?

Помимо упомянутых планов по приобретению новой системы АОИ, я назвал бы среди таких шагов организацию отмывки печатных узлов. Хотя мы в основном выполняем сборку по безотмывочной технологии, к нам всё чаще обращаются с заказами, включающими отмывку и нанесение влагозащитного покрытия. Сейчас в таких случаях мы пользуемся услугами контрагентов, но хотелось бы делать это у себя, чтобы обеспечить лучший контроль над качеством данных операций. Также прорабатывается вопрос приобретения установки лазерной резки трафаретов для нанесения паяльной пасты, что позволит значительно сократить сроки производства трафаретов

\section{Спасибо за интересный рассказ.}

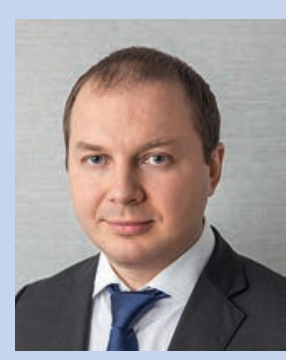

\section{Комментирует генеральный директор} 000 "АссемРус"

\section{Евгений Игоревич Матов}

Историю сотрудничества с ООО «Нанотех» я готов назвать идеальным примером взаимодействия с заказчиком с точки зрения поставщика оборудования. С самого начала руководство этой компании четко представляло, что именно им нужно, как должно выглядеть их будущее производство. Была четко сформулирована задача, обозначен бюджет, весь последующий диалог был абсолютно прозрачен и лишен «подводных камней». Наверное, так и должна выглядеть работа на открытом рынке.
Также я хотел бы отметить, что успех «Нанотеха» во многом был определен тем, что компания при формировании своих требований к составу основного и вспомогательного оборудования, дополнительных опций и программного обеспечения сразу учла специфику контрактного производства и не стала экономить на таких вещах, как дополнительные питатели или софт для подготовки программ вне линии. Часто компании в попытке сократить вложение средств на первом этапе концентрируются лишь на основном оборудовании, считая, что остальное можно докупить по мере необходимости. Но необходимость возникает с первого дня работы, и такой компании оказывается очень сложно занять конкурентные позиции.

Пример компании «Нанотех» показывает, насколько важно уделять внимание деталям и насколько начальные инвестиции упрощают жизнь, в особенности контрактным производителям. 


\section{КРЕМНИЕВЫЕ ЛАВИННЫЕ ФОТОДИОДЫ}

(функциональный аналог - фотодиоды ф. Hamamatsu)

Кремниевые лавинные фотодиоды КОФ102В, КОФ102В1 работают в диапазоне длин волн, $\lambda$, от 0,4 до 1,1 мкм. Диаметр активной области фотодиодов КОФ102В, КОФ102В1 - 200 мкм.

\section{Основные характеристики:}

- рабочее напряжение, U, порядка $180 \mathrm{~B}$;

- максимум спектральной фоточувствительности,

$\lambda \mathrm{s}$, от 0,82 до 0,88 мкм;

- коэффициент умножения, М, порядка 60;

- чувствительность к световому потоку, S, от 0,1 до 0,3 A/Bт.

\section{Область применения:}

- оптическая локация и дальнометрия; - регистрация ионизирующих излучений;

- в качестве современной альтернативы фотоэлектронным умножителям.

Таблица 1. Электрические параметры фотодиодов при Та $=25^{\circ} \mathrm{C}$

\begin{tabular}{|c|c|c|c|c|c|}
\hline \multirow{2}{*}{$\begin{array}{l}\text { Условное обозна- } \\
\text { чение фотодиода }\end{array}$} & \multirow{2}{*}{$\begin{array}{c}\text { Наименование } \\
\text { параметра, } \\
\text { единица измерения }\end{array}$} & \multirow{2}{*}{$\begin{array}{l}\text { Буквенное } \\
\text { обозначение }\end{array}$} & \multicolumn{2}{|c|}{ Норма } & \multirow{2}{*}{ Режим измерения } \\
\hline & & & не менее & не более & \\
\hline \multirow{3}{*}{$\begin{array}{l}\text { КОФ102В } \\
\text { КОФ102В1 }\end{array}$} & $\begin{array}{c}\text { Напряжение } \\
\text { лавинного пробоя, В }\end{array}$ & $U_{b}$ & 140 & 200 & $I_{b}=100$ MKA \\
\hline & $\begin{array}{c}\text { Коэффициент } \\
\text { температурного } \\
\text { изменения напряжения } \\
\text { лавинного пробоя, } \mathrm{B} /{ }^{\circ} \mathrm{C}\end{array}$ & $\mathrm{k}_{\mathrm{ur}}$ & 0,8 & 2,5 & - \\
\hline & $\begin{array}{l}\text { Максимальный } \\
\text { темновой ток, А }\end{array}$ & $I_{d}$ & - & $2 \cdot 10^{-7}$ & $U=0,1 U_{b}$ \\
\hline КОФ102B & \multirow{2}{*}{$\begin{array}{c}\text { Коэффициент } \\
\text { умножения }\end{array}$} & \multirow{2}{*}{ M } & 30 & - & \multirow{2}{*}{$\mathrm{U}=0,9 \mathrm{U}_{\mathrm{b}} \div \mathrm{U}_{\mathrm{b}}$} \\
\hline КОФ102В1 & & & 60 & - & \\
\hline $\begin{array}{l}\text { КОФ102B } \\
\text { КОФ102B1 }\end{array}$ & $\begin{array}{c}\text { Чувствительность к } \\
\text { световому потоку, А/Bт }\end{array}$ & s & 0,1 & 0,3 & $\begin{array}{c}U=0 B \\
M=1, \lambda=\lambda_{s}\end{array}$ \\
\hline
\end{tabular}

Таблица 2. Предельно догустимые значения электрических режимов эксплуатации фотодиодов

\begin{tabular}{|l|c|c|}
\hline \multicolumn{1}{|c|}{\begin{tabular}{|c|} 
Наименование режима эксплуатации, \\
единица измерения
\end{tabular}} & $\begin{array}{c}\text { Буквенное } \\
\text { обозначение }\end{array}$ & Hорма \\
\hline Максимально допустимое напряжение, B & $U_{\max }$ & $U_{b}$ \\
\hline Максимально допустимый темновой ток, мA & $\mathrm{I}_{\mathrm{dmax}}$ & 1 \\
\hline
\end{tabular}

Таблица 3. Справочные значения электрических параметров

\begin{tabular}{|c|c|c|c|}
\hline \multirow{2}{*}{$\begin{array}{c}\text { Наименование параметра, единица } \\
\text { измерения, режим измерения }\end{array}$} & \multirow{2}{*}{$\begin{array}{l}\text { Буквенное } \\
\text { обозначение }\end{array}$} & \multicolumn{2}{|c|}{ Норма параметра } \\
\hline & & не менее & не более \\
\hline Емкость, пФ, при $U=0,1 \cup_{b} B$ & C & 2 & 40 \\
\hline 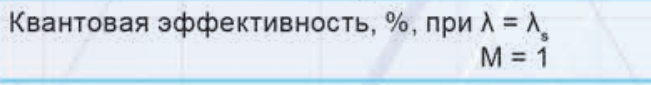 & QE & 50 & - \\
\hline Эквивалентная мощность шума, нВт & NEP & - & 20 \\
\hline Частота отсечки, МГц, при R = 1 кОм & $f_{c}$ & 1 & 50 \\
\hline
\end{tabular}

Таблица 4. Толщина кристалла, технологическая маркировка, координаты технологической маркировки

\begin{tabular}{|l|c|c|c|c|}
\hline Условное обозначение фотодиода & $\begin{array}{c}\text { Толщина } \\
\text { кристалла, мM }\end{array}$ & $\begin{array}{c}\text { Teхнологическая } \\
\text { маркировка }\end{array}$ & $\begin{array}{r}\text { Координаты технологической } \\
\text { маркировки (левый нижний угол) }\end{array}$ \\
\hline КОФ102B, КОФ102B1 & $0,4 \pm 0,01$ & LFD & 0,66 & Y, мM \\
\hline
\end{tabular}



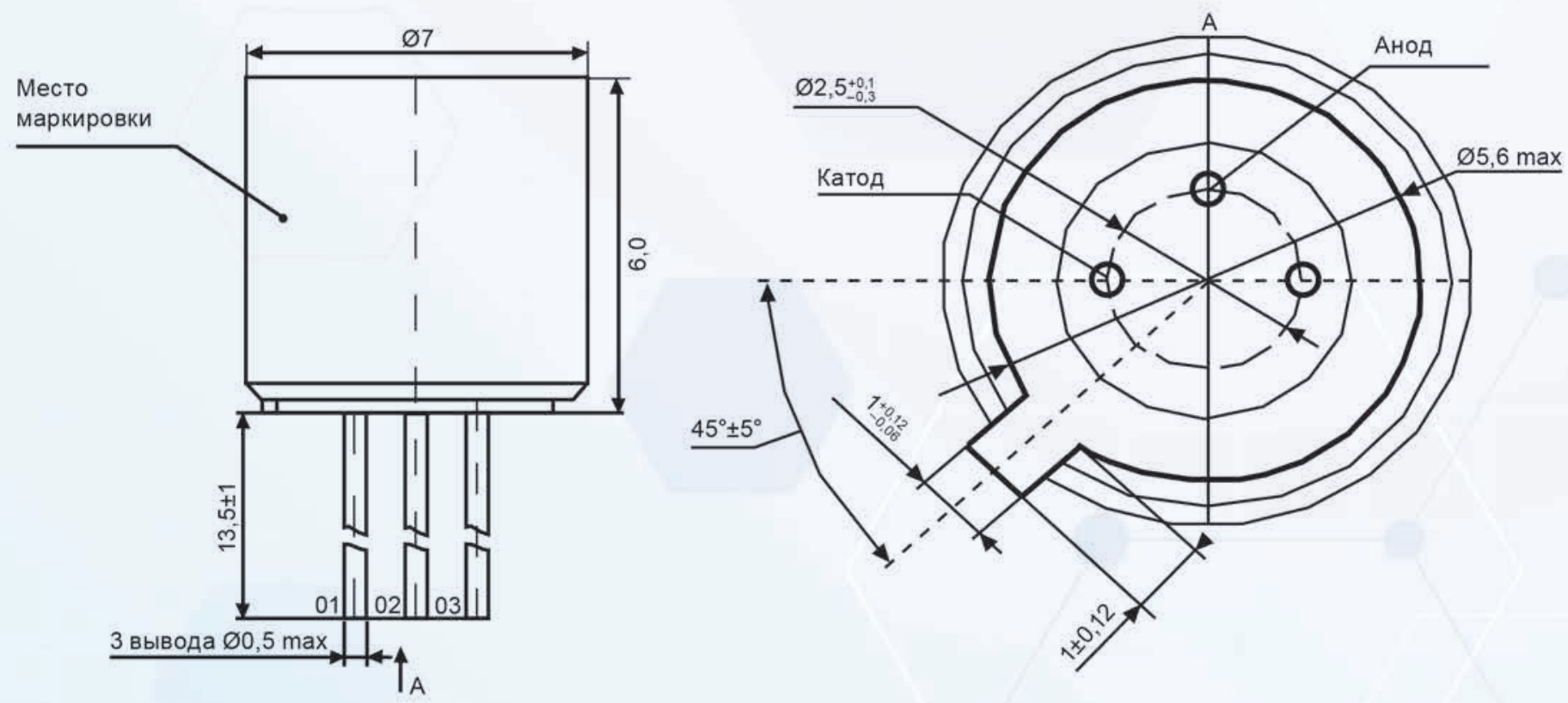

Рис. 2. Внешний вид кристалла

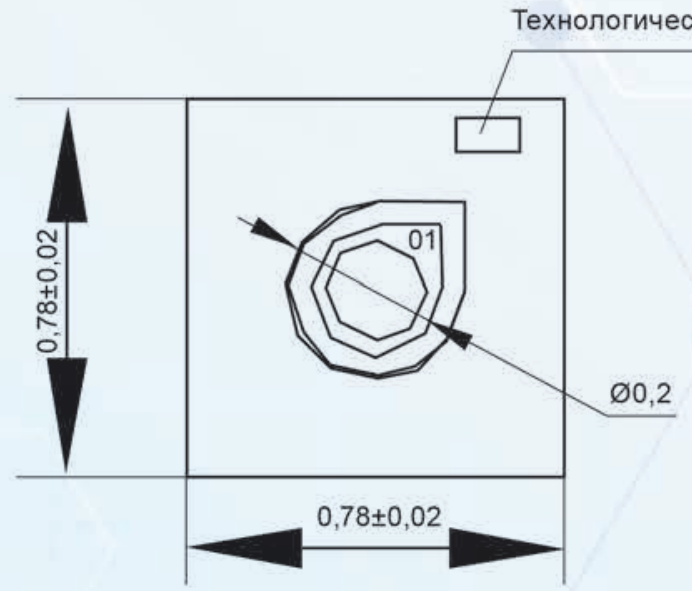

Таблица 5. Координаты контактных площадок

\begin{tabular}{|c|c|c|c|}
\hline \multirow[t]{2}{*}{ Условное обозначение фотодиода } & \multirow[t]{2}{*}{ Номер контактной площадки } & \multicolumn{2}{|c|}{$\begin{array}{c}\text { Координаты контактной } \\
\text { площадки (правый верхний угол) }\end{array}$} \\
\hline & & $\mathrm{X}, \mathrm{mM}$ & $y, m M$ \\
\hline \multirow{2}{*}{ КОФ102В, КОФ102В1 } & 01 & 0,461 & 0,461 \\
\hline & 02 & \multicolumn{2}{|c|}{ Обратная сторона кристалла } \\
\hline
\end{tabular}

Таблица 6. Состав и толщина слоев металлизации

\begin{tabular}{|c|c|}
\hline Толщина и состав металла на планарной стороне, мкм & $\mathrm{Al} 1,0 \pm 0,1$ \\
\hline & $\mathrm{Ti} 0,10 \pm 0,02$ \\
\hline & $\mathrm{Ni} 0,5 \pm 0,1$ \\
$\mathrm{Ag}$ & $0,6 \pm 0,1$ \\
\hline
\end{tabular}

\section{ОАО «ИНТЕГРАЛ» -}

управляющая компания

холдИнга «ИНТЕГРАЛ»

Республика Беларусь

E-mail:ATitov@integral.by тел./факс: (+375-17) 3987203

тел.: $(+375-17) 2989743$ www.integral.by 